\title{
Influence of Loading Quantity on the Properties of Quartz Sand Powder via Mechanical Ball Milling Method
}

\author{
Fang WANG ${ }^{1}$, Xiu-Qin WANG ${ }^{2}$, Chao $\mathrm{YANG}^{1}$, Jie-Guang SONG ${ }^{1, a,{ }^{*}}$ \\ and Hao HUANG ${ }^{1}$ \\ ${ }^{1}$ Engineering \& Technology Research Center for Materials Surface Remanufacturing of Jiangxi \\ Province, School of Mechanical and Materials Engineering, Jiujiang University, Jiujiang 332005 \\ China \\ ${ }^{2}$ Library, Jiujiang University, Jiujiang, 332005, China \\ a sjg825@163.com
}

Keywords: Mechanical ball milling, loading quantity, quartz sand, particle size.

\begin{abstract}
In order to improve the utilization and added value of the Yangtze river sand, the raw materials for preparing high performance quartz sand insulating brick were investigated, the following conclusions can be obtained through investigating the influence of mechanical milling loading quantity on performance of quartz sand powder. With the increase in milling added material, the average particle size of quartz sand is gradually increased. When the loading quantity is small, the powder particle size distribution is narrow, and when loading quantity is large, the powder particle size distribution is wider. With the increase of milling added material, quartz sand powder high cone decreases, namely quartz sand powder flowability loading quantity increases gradually changed for the better. With the increase of quantity of milling device, tap density of quartz sand powder increases. However, when loading quantity higher than $200 \mathrm{~g} / \mathrm{L}$ ball milling, quartz sand tap density increased considerably larger. Comprehensive consideration the overall process, milling loading quantity was $200 \mathrm{~g} / \mathrm{L}$ preferably, the average particle diameter of quartz sand powder is $11.21 \mathrm{um}$.
\end{abstract}

\section{Introduction}

With the rise of industrial science and technology, gradually into industrial raw materials a greatly increased demand period, a variety of high quality can be utilized natural or synthetic mineral raw materials are widely utilized in industrial production, high-grade quartz sand is one of [1-4]. With advances in technology and high-grade natural resource consumption, many emerging industries attendant, in these industries, the vast majority of the use of industrial waste or low-grade raw material for preparing high cost of "green" products [5-6] . Mixing mortar material part quartz sand is used for housing construction, so that the lower cost value of quartz sand, hardly reflect its economic value [7-8].

The gradual depletion of raw materials for the current, low quality and saving clay resources for the purpose of state strongly encourage the use of low-grade waste even to develop new building materials, to achieve the purpose instead of clay building materials [9-11]. To address the shortage of supplies of raw materials, quality improvement, conservation of land resources and improve the economic value of low-grade quartz sand for the purpose of the use of low-grade quartz sand along the Yangtze River to develop new building materials [12-14]. This paper studies the influence of the number of revolutions of the milling low-grade quartz sand powder properties, laying the foundation for a high-performance raw materials.

\section{Materials and Experimental}

To the future of low-grade quartz sand along the Yangtze River in the sun to dry, first on low-grade quartz sand raw materials roughing, followed by a 50-mesh sieve to filter, so that the size of sand particles larger particulate mineral removal, to avoid affecting milling . After finally put QM-BP type planetary ball mill pot, the milling time as $60 \mathrm{~min}$, milling speed $300 \mathrm{r} / \mathrm{min}$, the size of the ball mass 
ratio of 0.75 , a quartz sand ore milled under different milling conditions added material remove spare quartz sand powder, with BT-9300H type particle size analyzer quartz sand milled particle size analysis, with the Czech TESCAN VEGA II type scanning electron microscope morphology. The tap density test method by volume powder. Supreme Court with cone test powder flowability, powder cone higher, reflecting powder flowability worse.

\section{Results and Discussion}

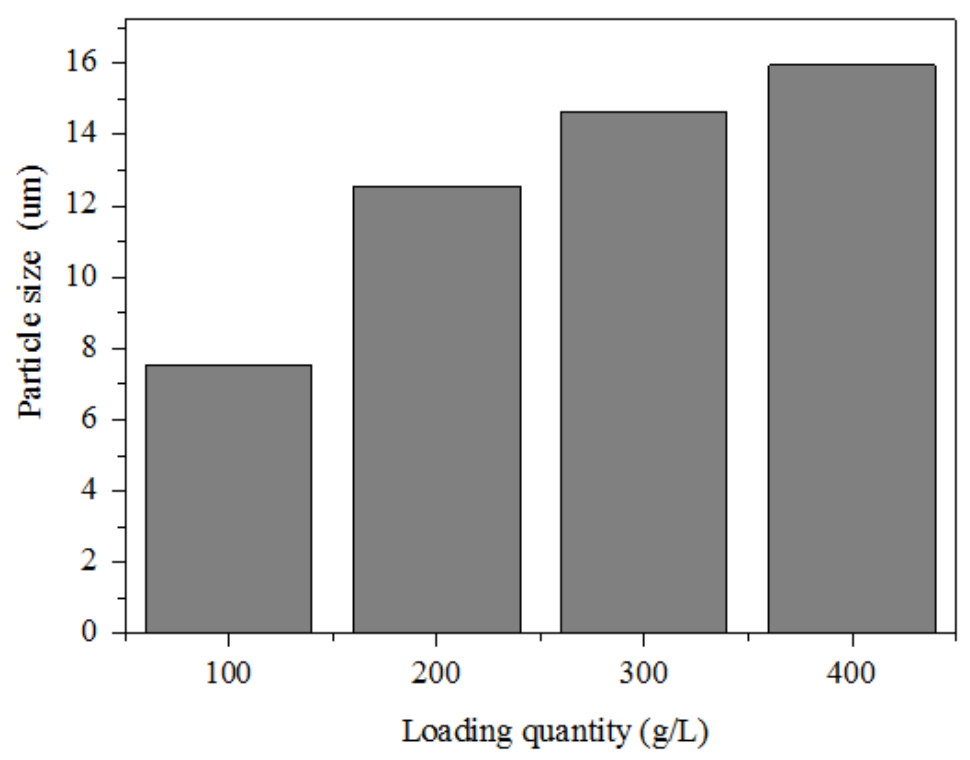

Fig.1 Effect of ball milling loading quantity on the average particle size of quartz sand powder

The relative between quartz sand powder particle size and loading quantity is shown in Fig.1, when loading quantity of $100 \mathrm{~g} / \mathrm{L}$, the average particle size of $7.53 \mathrm{um}$, when the loading quantity of $200 \mathrm{~g} / \mathrm{L}$, the average particle diameter of $11.21 \mathrm{um}$, when the loading quantity of $300 \mathrm{~g} / \mathrm{L}$, the average particle diameter of $14.89 \mathrm{um}$, when the ball loading quantity of $400 \mathrm{~g} / \mathrm{L}$, the average particle diameter of 15.94um. From the results obtained the following law, the average particle size of quartz sand is gradually increased with the increase of the added material milling. Because the loading quantity increases, the ball material ratio decreases as constant milling media, the number and impact of abrasive quartz sand milling media weakened, so that the average particle size of the quartz sand increases, namely milling effect of variation.
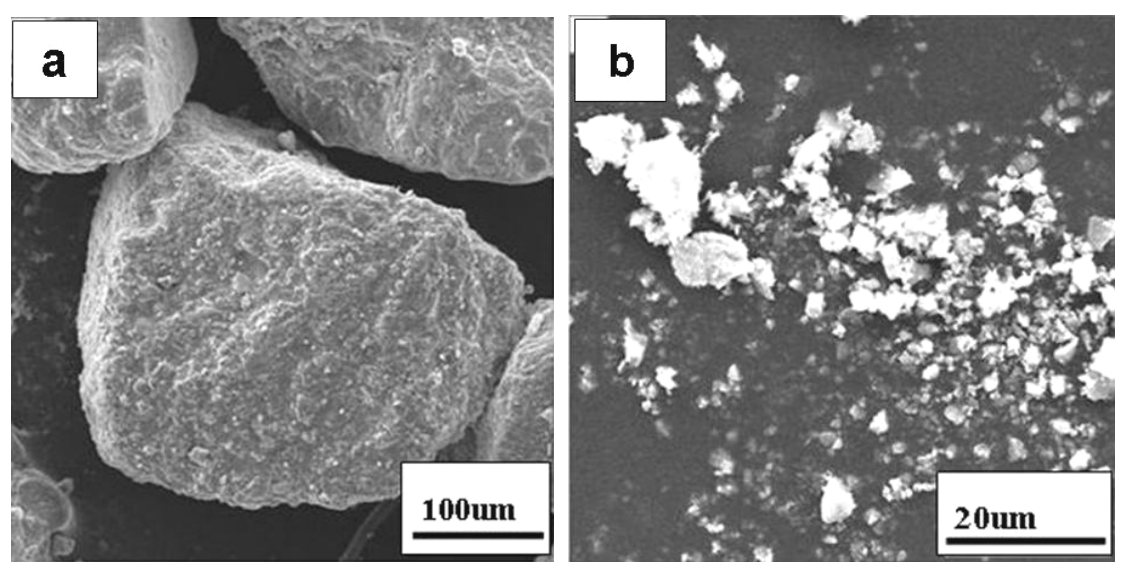

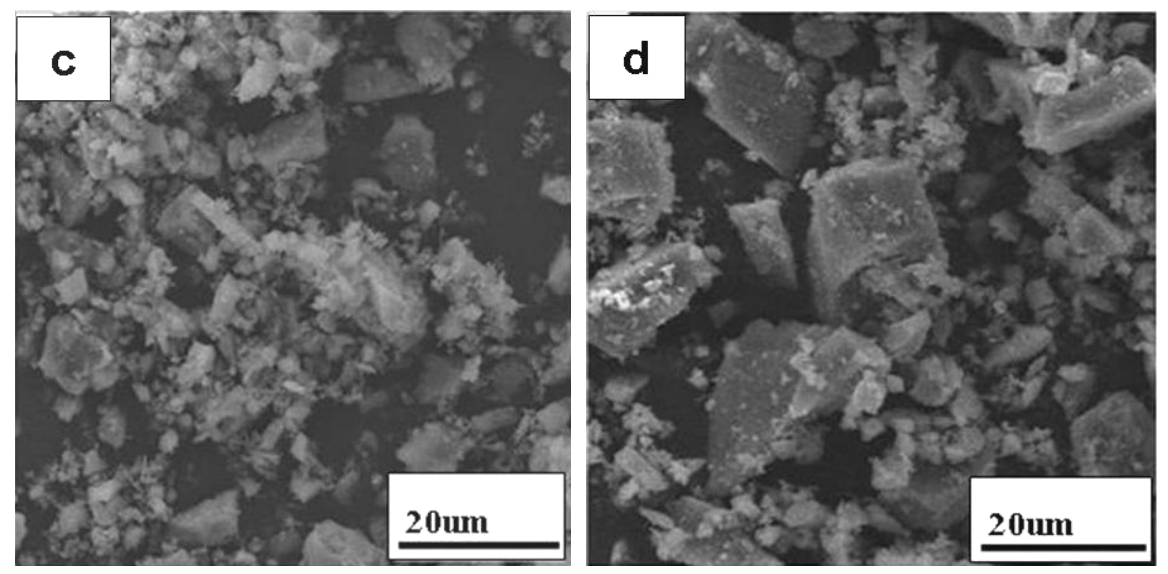

Fig.2 Effect of ball milling loading quantity on the microstructure of quartz sand powder

The influence of loading quantity on microstructure of quartz sand powder is shown in Fig.2, Fig.2 a, b, c and d is shown the original quartz sand and the loading quantity of 100,200 and $400 \mathrm{~g} / \mathrm{L}$, respectively. The particle size results seen from the Fig. 2 is consistent with the results of particle size analysis, but may also be derived from this figure size distribution results, when loading quantity is small, the powder particle size distribution is narrow, and when loading quantity is large, the powder particle size distribution is wider. This is mainly due to the added material is small, the milling media in the ball mill jar single particles of quartz sand powder were impact milled and greatly increase the chance of breaking [15-16], so it is easy to obtain a narrow particle size distribution quartz sand powder. Conversely, loading quantity is large, a single milling medium grained quartz sand powders were impact, grinding and crushing odds greatly reduced, thus it is easy to obtain a wide particle size distribution of quartz sand powder.

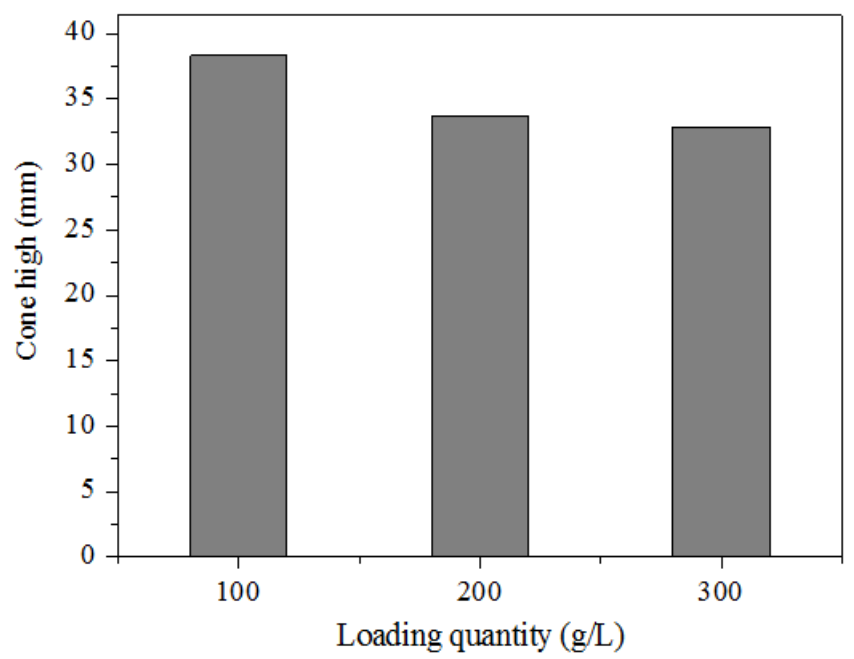

Fig.3 Effect of ball milling loading quantity on the cone high of quartz sand powder

From Fig.3, quartz sand powder cone high is decreased with the increase of loading quantity, that is to say the flowability of quartz sand powder is the better with the increasing loading quantity gradually. However, compared with $300 \mathrm{~g} / \mathrm{L}$ loading quantity, when ball milling loading quantity is $200 \mathrm{~g} / \mathrm{L}$, quartz sand mobility decreased greatly. Because with loading quantity increases, quartz sand milled powder particles increases and the surface area decreases, powder or adsorbed moisture content of the surrounding gas is reduction, thereby weakening the adhesion between the particles resulting in better mobility. When quartz sand powder particles is reduced to a certain extent, the particle size increases the speed slows, the adhesion between the particles decrease speed slows, so better mobility rate slows. Plus upload large quantity, quartz sand powder particle size distribution is wide, wide gap between the size of the particles, large particles flow better, less liquid small particles, so that the quartz sand powder good liquidity, while loading quantity is small, quartz sand powder 
particle size distribution is narrow, only a relatively small part of the large particles, so that the powder fluidity.

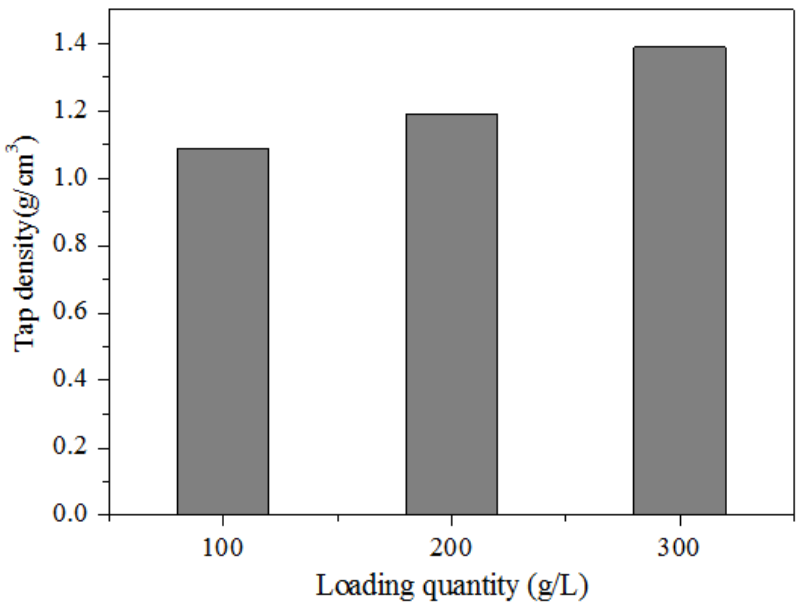

Fig.4 Effect of ball milling loading quantity on the tap density of quartz sand powder

Fig.4 shows that the tap density of quartz sand powder increases with the increase in quantity of milling device. However, when loading quantity higher than $200 \mathrm{~g} / \mathrm{L}$ ball milling, quartz sand tap density increased considerably larger. This is because with the increase of added material, so that the quartz sand particle size increases, the specific surface area of the powder decreases, mutual adhesion tendency gradually weakened, so that the powder becomes small chance to reunite with each other, the small pores is formed between the aggregate powder, which eventually leads to increased tap density. When the added material is large, quartz sand powder particle size distribution is wide, with a certain level between the large-diameter powder with a small particle size powders such high tap density powder, when added material when the small particle size distribution of quartz sand powder gradually narrowed, is formed between the large particles and small particles gradation is eliminated, away from the closest packing powder way, resulting tap density decreases.

The quartz sand particle size gradually increased drastically reduced with the increase of added material in other parameters unchanged. When less added material, relatively fast speed grinding bodies and the material attached to the cylinder with the operation, would not achieve the abrasive effect. Added material is higher, relative speed is too slow grinding of abrasive material force, but would not achieve the role of impact, impact grinding efficiency. When moderate added material, while grinding the material with the impact and abrasive, comprehensive consideration of the entire process, milling canned quantity was $200 \mathrm{~g} / \mathrm{L}$ is better.

\section{Conclusion}

Through the results and anlysis, the conclusions are shown, the average particle size of quartz sand is gradually increased with the increase in milling added material. When the loading quantity is small, the powder particle size distribution is narrow, and when loading quantity is large, the powder particle size distribution is wider. With the increase of milling added material, quartz sand powder cone high decreases, namely quartz sand powder flowability loading quantity increases gradually changed for the better. With the increase of quantity of milling device, tap density of quartz sand powder increases. However, when loading quantity higher than $200 \mathrm{~g} / \mathrm{L}$ ball milling, quartz sand tap density increased considerably larger. Comprehensive consideration the overall process, milling canned quantity was 200g/L preferably.

\section{Acknowledgements}

The authors are thankful for the financial support provide by the Science and Technology Found of Educational Department of Jiangxi Province, China (KJLD12096), the Industry Science and Technology Found of Jiujiang city, China (JST2009-86-06), the Science and Technology Found of 
Jiujiang University, China (2015LGYB11), the National Found for Student Innovation and Creation of Local University of China (201311843007) and the Natural Science Found of Guangxi Province, China (2014GXNSFAA118314).

\section{References}

[1] H. B. Ling, Q. Li, J. Zhang, Preparation of quasi-ternary Fe-P-C bulk metallic glass using industrial raw materials with the help of fluxing technique, Adv. Eng. Mater. 17 (2015) 1045-1050.

[2] R. I. Iacobescu, G. N. Angelopoulos, P. T. Jones, Ladle metallurgy stainless steel slag as a raw material in ordinary Portland cement production: a possibility for industrial symbiosis, J. Clean. Product. 112 (2016) 872-881.

[3] C. J Shi, Z. M Wu, J. F. Xiao, D. H Wang, Z. Y. Huang, Z. Fang, A review on ultra high performance concrete: Part I. Raw materials and mixture design, Constr. Build. Mater. 101 (2015) 741-751.

[4] H. B. Wang, L. X. Ma, L. Li, B. Zhang, Fabrication of Fe-based bulk metallic glasses from low-purity industrial raw materials, J. Alloy. Compd. 629 (2015) 1-4.

[5] H. M. Algin, P. Turgut, Cotton and limestone powder wastes as brick material, Const. Build. Mater. 22 (2008) 1074-1080.

[6] M. Raimond, M. Dondi, F. Mazzant, Equilibrium moisture content of clay bricks: The influence of the porous structure, Build. Environ. 42 (2007) 926-932.

[7] C. Helbig, L. Wietschel, A. Thorenz, A. Tuma, How to evaluate raw material vulnerability - An overview, Resources Policy, 48 (2015) 13-24.

[8] F. D. Benedetto, E. Gazzano, M. Tomatis, F. Turci, L. A. Pardi, Physico-chemical properties of quartz from industrial manufacturing and its cytotoxic effects on alveolar macrophages: The case of green sand mould casting for iron production, J. Hazard. Mater. 312 (2016) 18-27.

[9] R. G. Popa, L. G. Popescu, T. A. Abagiu, Aspects Regarding the use of the industrial wastes as raw materials for the manufacture of building materials, Metalur. 54 (2015) 297-300.

[10] D. Grover, C. R. Savidge, L. Townsend, O. Rosario, L. B. Hu, D. M. Rizzo, M. M. Dewoolkar, Surface permeability of natural and engineered porous building materials, Const. Build. Mater. 112 (2016) 1088-1100.

[11] M. Sutcu, H. Alptekin, E. Erdogmus, Y. Er, O. Gencel, Characteristics of fired clay bricks with waste marble powder addition as building materials, Const. Build. Mater. 82 (2015) 1-8.

[12] Z. J. Liu, H.Q. Huang, S. E. Werners, Construction area expansion in relation to economic-demographic development and land resource in the Pearl River Delta of China, J. Geograph. Sci. 26 (2016) 188-202.

[13] F. Wang, L. C. Miao, Y. J. Zhang, A simplified method to predict creep behavior of the Yangtze River sand, Bull. Eng. Geology Environ. 71 (2012) 317-324.

[14] S. Platias, K.I. Vatalis, G. Charalampides, Suitability of Quartz Sands for Different Industrial Applications, Proced. Econom. Finan. 14 (2014) 491-498.

[15] Q. Y. Li, S. C. Liu, S. R. Li, Preparation of micro-size flake silver powder by planetary ball mill, J. Mater. Sci. 27 (2016) 452-457.

[16] J. Tang, T.Y. Chai, Z. Liu, Selective ensemble modeling based on nonlinear frequency spectral feature extraction for predicting load parameter in ball mills, Chin. J. Chem. Eng. 23 (2015) 2020-2028. 